\title{
Test of Arbitrage Pricing Theory on the Tehran Stock Exchange: The Case of A Shariah-Compliant Close Economy
}

\author{
Pooya Sabetfar (Corresponding author) \\ Faculty of Economics and Management, University Putra Malaysia, 43400 Serdang, Selangor, Malaysia \\ Tel: 60-17-389-1012Ｅ-mail: psabetfar@yahoo.com \\ Dr. Cheng Fan Fah \\ Faculty of Economics and Management, University Putra Malaysia, 43400 Serdang, Selangor, Malaysia \\ Tel: 60-16-696-5840 E-mail: chengfanfah@yahoo.com \\ Dr. Shamsher Mohamad, Professor \\ Deputy Dean, GSM, University Putra Malaysia, 43400 Serdang, Selangor, Malaysia \\ Tel: 60-16-696-5840Ｅ-mail: shamsher57@yahoo.com \\ Dr. Bany Ariffin Amin Noordin \\ Faculty of Economics and Management, University Putra Malaysia, 43400 Serdang, Selangor, Malaysia
}

Tel: 60-13-349-3451Ｅ-mail: banymn@yahoo.com

Received: November 2, 2010

Accepted: November 15, 2010

doi:10.5539/ijef.v3n3p109

\begin{abstract}
This paper provides weak evidence in support for the application of Arbitrage Pricing Theory (APT) on the Iranian

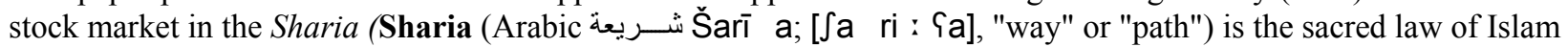
faith.) based close economy. Tests conducted using the principal component analysis and canonical correlation model showed that at least one to three factors that can explain the cross-section of expected returns in this market. Financial and economical sanctions possibly explain the negative stock market returns which reflect the reaction of investors to the announcement of sanctions. Overall, the results suggest that there are four groups of macroeconomic variables in the test period that affect stock returns for the test period, 1991 to 2008, but the significance of these factors is not consistent over time. In general the findings document a weak applicability of APT in this market.
\end{abstract}

Keywords: Full Sharia economy, Sanction, Canonical Correlation and Arbitrage Pricing Theory

Acknowledgement: We wish to thanks Dr. M. Arif, Dr. Annuar, and. Dr. Law S.H. and Dr.Taufik for their contribution on the earlier draft of this paper.

\section{Introduction}

The two major theories on equilibrium pricing of securities are Capital Asset Pricing Model (CAPM) extended by Sharp (1964), Lintner (1965), Mossin (1966) and Black, Jensen and Scholes (1972) and the Arbitrage Pricing Theory (APT). The CAPM, suggests that only non-diversifiable market risk influences expected security returns. The Arbitrage Pricing Theory (APT) suggested by Stephen A. Ross (1976) does not restrict to market risk but many micro and macro factors could affect stock returns. Furthermore, theoretical investigations relate variability in expected rate of return to intertemporal varieties in macroeconomic variables. Therefore APT gives a better justification for returns than any other market proxies (Elton, Gruber, and Blake, 1995).

Financial markets are fundamental to the development of any economy and are affected by national and global events. Events such as war, crisis, sanction and revolution can adversely affect the financial markets and consequently the economy. The Islamic revolution of Iran in 1979, had a crucial effect on the economy and financial sector of Iran. It changed many policies and economic decisions of the country which in turn affected the financial market of Iran. Iran is an Islamic state and applies Islamic law (Sharia) to all spheres of national development including the economic activity and private businesses. The government of Iran has even nationalized all of the 
country's banks and set prices and subsidizes in most industries. The country's financial institutions are not allowed to activity that can be construed as Riba, and banks offer interest-free deposits and profit sharing in their business ventures. Tehran Stock Exchange is the main capital market of Iran which is run based on Islamic law. The investors cannot borrow on interest to finance their investments, and therefore cannot trade on margin i.e., borrow to purchase shares. Conventional hedge funds, arbitrage funds, short term speculation and funds are prohibited for investors as they all borrow heavily in order to finance their investment.

The war between Iran and Iraq (1980-1989) and the world sanctions against Iran after revolution adversely affected the Iranian economy which in its turn affected Tehran stock exchange as an important source of capital for growth. Alikhani (2000) finds that the US sanctions have been causing some economic and financial damages to the Iranian economy and has increases the volatility of the macroeconomic variables in Iran. The financial sanctions' impact on Iran has been greater than those due to the economic sanctions. The financial sanctions have curtailed Iran's ability to borrow funds to finance its development projects. Because of the sanctions, Iran has paid higher rates of interest on its loans and has guaranteed excessively high rates of return on investment on its projects (Torbat, 2006). The sanctions on Tehran stock market, have caused a high degrees of economic instability, might have a remarkable influence on the set of variables that proxy for factors in equity risk. These effects have made the investment decision in Iran more complicated because the risks are difficult to evaluate and often non-quantifiable (Hakim, 2008). Changes in macroeconomic variables do affect stock market returns and its volatility (risks). This study intends to ascertain the determinants of asset returns in this shariah based close economy using the APT approach, specifically, the returns on the stocks listed on the Teheran Stock Exchange. There is no documented comprehensive evidence on similar issue in Tehran stock exchange market and the existence of arbitrage opportunity in the Iranian stock market during sanctions period will also be examined. The findings will contribute on the verification of the theory in different economic settings.

The paper is organized as follows: Section two summarizes the evidence on APT; Section three explains the data and methodology; Section four presents the findings; and Section five concludes the paper.

\section{Literature review}

The APT has been extensively tested in developed markets since it was first proposed in 1976. The earliest tests used the factor analytic (FLM) approach pioneered by Gehr (1978) and later extended by Roll and Ross (1980). Later empirical work increasingly used the macroeconomic variables model. Chen, Roll and Ross (1986) first used this pre-specification of macro variables approach in 1986. Empirical tests using factor analysis or principal components analysis primarily involve determination of the number of significant factors (by determining the number of risk premium, $E_{i}-E_{o}$, which are significantly different from zero) and determining whether the constant, $E_{o}$ is the same across securities groups. The earliest tests were conducted by Roll and Ross (1980) who tested the APT using maximum likelihood factor analysis on daily US data from 1962 to 1972.

After the seminal paper, many other researchers applied the APT with difference methodology. For example, Connor and Korajczyk (1986) used the principal component analysis proposed by Chamberlain and Rothchild (1983) and documented five factors explaining the asset returns. Kryzanowski and To (1983) tested APT on the Canadian data and found that, on average, the number of factors explaining returns remain approximately the same across various samples of the same size and across various time intervals, except that the numbers of significant factors increase with group size. Burmeister and McElory (1988) tested APT based on the macro economic variables identified by Chen, Roll and Ross (1986). Overcoming the errors- in-variables difficulty of the two-stage regression method, they employed the simultaneous approach first recommended by McElory, Burmeister, and Wall (1985). The simultaneous estimation was achieved employing repeated Nonlinear Seemingly Unrelated Regression.

Chen and Jordan (1993) study the contrasting models directly, i.e. the FLM and Macroeconomic Variable Model (MVM) modeling of the APT and tested their relative magnitude to describe and forecast security returns. They employed the two-stage regression process. They found that little was missing in moving from FLM to the MVM, and the MVM may appear to be the better model when the two were tested against a proposed sample or against a test period. Garrett and Priestley (1997) demonstrated that statements about whether the factor structure was strict or estimated do matter in determining the significant macroeconomic factors. Employing U.K. data, they explained that none of the factors were priced when returns were presumed to have a strict factor structure. Nevertheless, if an approximate factor where idiosyncratic returns were permitted to be simultaneously correlated across securities were presumed, six factors were priced, via unexpected inflation, industrial production, the money supply, default risk, the exchange rate and excess returns on the market portfolio. Van Rensburg (2000) examined the Chen, Roll and Rose (1986) pre-specified variable procedure to priced APT identification on the Johannesburg Stock Exchange 
(JSE) using the Vector Autoregressive Regression (VAR) methodology and demonstrated that a two indices model had better explanatory power on equity returns.

In Iran, Mohseni (2007) applied the APT on selected firms in the Tehran stock exchange using the Fama and Macbeth(1973) methods using monthly data. The two risk factors were measured for these groups of firms (money supply and oil price) and the sensitivity of each firm's return was estimated by the two factors and documented that APT model was significant in explaining the returns on his selected sample of firms.

\section{Methodology and Data Analysis}

The Tehran Stock Exchange (TSE) was founded in February 1967 and began its first year of activity with only five companies. As of April 2009, there are 421 companies listed on the TSE with a total market capitalization of US\$52,452.5 million. (TSE yearly bulletin, 2009). In the Middle East countries, TSE is ranked $17^{\text {th }}$ based on market capitalization as a percent of GDP.

Iran has a different calendar from the other countries. Its Calendar based on Hegri Shamsi that the beginning of the year is in the $20^{\text {th }}$ March and ended on $19^{\text {th }}$ March of the year which firms should have activities based on this calendar in TSE. The analysis period in this study, covers 17 years from $20^{\text {th }}$ March 1991 to $19^{\text {th }}$ March in 2008. This is so far the most comprehensive test of APT in this market. Due to the economic sanctions and 1997 crisis as well as financial sanction, the analysis is divided into two periods, 1991-1998 and 1999-2008, respectively. As a result of the availability of smaller stocks on the main board of the TSE in the earlier years, the number of stocks in the sample was consequently limited. The stocks chosen in this research are taken randomly from Main Board of Tehran Stock Exchange Market (TSE). Nevertheless, there are 80 stocks chosen, 20 stocks were removed because of the incomplete information. A total of 60 stocks were selected in full and first sub period. Since the number of securities increased for the period beyond 1998, 160 stocks were chosen for the second sub-period.

The main objective of this study is to test APT in the Tehran Stock Exchange (TSE) using unidentified factors and macroeconomic variables. This study also examines the impact of economical and financial sanctions on stock market returns. This is done first by identifying the macro APT-relevant factors that affect security returns, and after which extending the factor matrix to include factor(s) relevant to less developed economies.

In the above section, it was shown that different methodologies and research designs have been used to test APT in different markets. This study tests the APT using factor analysis with principal component analysis and Canonical Correlation Analysis (CCA). The test is carried out before and after a financial crisis that destabilized the economy to ascertain the impact of the structural changes in the economy and the securities market as a consequence of the crises.

The stock price data for this study are the monthly returns on stocks on the main board of the TSE. The returns are calculated using month-end prices, i.e., $R_{t}=\left(P_{\mathrm{t}}-P_{\mathrm{t}-1}\right) / P_{t-1}$, where $R_{t}$ is the return per period $t$ for the period being computed, $P_{\mathrm{t}}$ is the price of the stock at the end of the period t., and $P_{\mathrm{t}-1}$ is the price of the stock at the end of the period $\mathrm{t}-1$. The returns are adjusted for dividends, bonus issues, rights issues and stock splits.

Based on the studies by Chen, Roll and Rose (1986), Clare and Priestley (1998) and Mohseni (2007), a variety of macroeconomic and financial factors and a proxy for the market were selected, inclusive those factors that are peculiar to TSE. Variables selected were Consumer Price Index (CPI), Trade Balance, Money Supply $\left(\mathrm{M}_{1}, \mathrm{M}_{2}\right)$, Exchange Rate (Rial / US\$), Central Bank Reserve, Volume of Stock Transaction of TSE, Tehran Price Index (TEPIX), Oil Price, Production of Crude Oil, Export of Crude Oil, Gross Domestic Product (GDP) and Profit rate proxy (ROE of banks). Monthly data was used and all the economic variables are measured by rate of change rather than absolute values.

The procedure to test the APT is as follows: First, factor analysis with Principal Component Analysis (PCA) was applied to determine the individual securities and portfolios factor loadings estimates to explain the cross-sectional variation of individual and portfolios estimated returns. Second, cross-sectional regressions were run to determine the number of priced factors to measure the size and statistical significant of risk premium associated with the estimated factors from the common factors extracted in the first stage. This procedure repeated for individual securities and different size of portfolios for full period and two sub-periods separately. The reasons why stocks are grouped into portfolios are to eliminate diversifiable risk and to reduce the errors-in-variables problem in the second stage cross-sectional regression; this is an established procedure. This study stocks ordered by size and also, employing different size of portfolios increase the reliability of the results.

In the first stage, the principal component factor analysis procedure will describe the return in the following way:

$$
\mathrm{R}_{\mathrm{it}}=\mathrm{b}_{\mathrm{i} 1} \mathrm{PC}_{1}+\mathrm{b}_{\mathrm{i} 2} \mathrm{PC}_{2}+\mathrm{b}_{\mathrm{i} 3} \mathrm{PC}_{3}+\ldots+\mathrm{b}_{\mathrm{ik}} \mathrm{PC}_{\mathrm{k}}
$$


Where, $R_{i t}=$ is individual securities or portfolios return; $b_{i k}=$ is known as factor loadings, which can be used to represent the sensitivity of the security again the asset i's returns to the movements in the common factors; $\mathrm{PC}_{\mathrm{k}}=$ is the principal component scores of asset i. To test general hypothesis in this study is to identify $b$ 's are priced in the arbitrage pricing relationship. Thus, in this study, the $b$ 's will be used to test the pricing of risky factors. This traditional test using the APT is usually undertaken by implementing a cross-sectional regression procedure used in Black, Jensen and Scholes (1972) and Fama and MacBeth (1973) methodology in the following way:

$$
\mathrm{E}\left(\mathrm{R}_{\mathrm{it}}\right)=\lambda_{0}+\Sigma_{\mathrm{k}=1}^{\mathrm{k}} \lambda_{\mathrm{k}} b_{\mathrm{ik}}
$$

If APT is valid, at least one number of priced factors must be statistically significant. This study utilized the pvalues to determine the significance of the individual risk premia and vector of risk premia respectively.

\section{Results and Discussions}

This section discusses the findings.

\subsection{Results of Factor analysis and Cross-Sectional Regression of average returns against factor scores coefficients}

\subsubsection{Full Period (1991-2008)}

Identification of factors required forming portfolios of firms with different size. The sample of 60 firms for the 1991-2008 periods were classified into portfolios of various sizes and the results are presented in Table 1. The Kaiser-Meyer-Olkin test (KMO) value was 0.63 to 0.85 and the Bartlett's test of sphericity was significant at above the 99 percent acceptance level indicating the appropriateness of principal components factor analysis for this data set. The analysis identified 22 to 2 factors based on the identification criterion that the eigenvalue for factor selection must exceed 1 . The sixty individual securities explained 71 percent of variance in returns, the twenty non overlapping portfolios (every portfolio formed from 3 securities) explained 62.8 percent, the fifteen non overlapping portfolios (every portfolio formed from 4 securities) explained 54 percent, the ten non overlapping portfolios (every portfolio formed from 6 securities) explained 50 percent, the five non overlapping portfolios (every portfolio formed from 12 securities) explained 81 percent of variance in returns. These findings are consistent with findings in other markets: e.g. a UK study, Garrett and Priestley (1997) using 80 stocks identified 20 factors that explained a majority of the return variance in that market.

The cross-section regression of the mean stock returns indicated that the factors are jointly significant as evidenced by an $F$-value, which is well above the acceptance level of 0.000 . On an individual and portfolios factor basis, nine to two factors were found to significantly affect the prices: the $t$-values ranged from 2.36 to 12.25 , all above the critical value for five percent level of significance for the sample. The financial and economical dummy variables are significant in most of the samples. Both type of sanctions had a negative impact on Stocks listed on the TSE. The opposing signs of market reactions in Iran suggest that Iranian investors were acting as close substitutes. The adjusted $R$-squared value was high from 0.93 to 0.99 percent.

\subsubsection{First Sub- Period (1991-1998)}

A similar analysis was carried out for this sub period, analysis. This is to investigate the effects of using a shorter period as compared to full period, and evaluate the APT before the Asian financial crisis. First, the number of factors extracted based on the Kaiser criterion increase with increase in sample size predicted. The sixty individual securities explained 72 percent of variance in returns, the twenty non overlapping portfolios explained 65 percent, the fifteen non overlapping portfolios explained 66 percent, the ten non overlapping portfolios explained 65 percent, and the five non overlapping portfolios explained 69 percent. The cross-sectional performance of the model for this sub-period was almost same but a small number of factors were extracted in the first stage principal components analysis, one to eight were found be priced at one and five percent level.

The economical dummy variable is significant at one, five or ten percent level for twenty, ten and five portfolios. It felt that the market reacted sharply to the new information and caught investors off guard. The financial dummy variable is significant at one, five or ten percent level for five portfolios. The stock market's investors reacted negatively to the news of the sanctions. These results are important to quantify the change in the systematic risk of these markets over time, and shed light on how investors react to such events. The joint F-test of significant also display one hundred significant results for the all the samples. The explanatory power in terms of adjusted $\mathrm{R}$-squared values is in tandem with performance as indicated by F- test with those significant samples having value ranging from 0.084 to 0.99 (See Table 2).

Compared to the full 17- year period, the number of factors extracted initially from factor analysis appears to be smaller for the same sample size. Also, the number of the priced factors in the cross-sectional regression was 
comparatively smaller for similar sized sample. Performance measured by F-test and adjusted R-squared values were also relatively poor.

\subsubsection{Second Sub- Period (1999-2008)}

A similar analysis was repeated for the second period with 160 securities. For this sub-period, the number of factors extracted based on the Kaiser criterion increased with sample size that is higher than both the first sub-period and 17 -year period. The one hundred sixty individual securities explained 66 percent of variance in returns, the twenty non overlapping portfolios explained 66 percent, the fifteen non overlapping portfolios explained 67 percent, the ten non overlapping portfolios explained 66 percent, and the five non overlapping portfolios explained 61 percent. One of the sample sizes showed significant negative impact of financial and economic sanctions. In terms of cross-sectional explanatory power measured by adjusted R-squared values, this sub-period displayed the worst result compared to the earlier periods, comparable to that using the 17-year period (See Table3).

\subsection{Results of the factor Structure of the Iranian Economy}

The objective of this section is to identify set Iranian macroeconomic variables that represent the Iranian economy that can explain equity returns on the TSE. Thirteen macroeconomic variables that covered a wide spread of economic process and selection of the economy were analyzed. The overall results from the principal component analysis shows the thirteen macroeconomic variables were grouped into four, five and four factors for full, first subperiod and second sub- period respectively. In the full period the first factor explained highest variance of Iranian economy. The most important factors are money variables in the 17 -year full period. The most important factor in the first sub-period is factor one that includes the variables related to oil. Oil price is the most important factor in Iranian economy in this period. However, trade balance is most important of the first factor in second sub period. It is appear that money and oil variables are most important variables that explained fluctuation in Iranian economy (See Table 4).

\subsection{Results of Canonical Correlation Analysis}

The Canonical Correlation Analysis showed the relationship between Iranian stock market returns and macroeconomic variables. Interpretation of the two significant canonical variates from loading are based on 0.3000 and above of canonical variates. Both the direction of correlation in the loadings matrices and the direction of scales of measurements are considered when interpreting the canonical variates (Tabachnik and Fidell, 1996). The first canonical variate formed the stock market returns are the most successful linear combination of the security to predict the first canonical variate formed from the macroeconomic variables. Findings summarized in Table 5 demonstrate that, the factor structure of the Iranian economy in the full period is the fourth factor composed of Export of crude oil and profit rate proxy (ROE of banks). Table 6 shows that TEPIX, Central Bank Reserves and GDP are the factor structure of the Iranian economy in the first sub-period. Money supply (M2), Money supply (M1), Consumer Price Index and GDP are the factor structure of the Iranian economy in the second sub-period (See Table7). The results illustrates that the value of standardized variance of the principal component scores of stock market returns explained by their own canonical variate and the opposite of canonical variate (redundancy) are increased by reducing the number of samples in most of the cases in the all periods. However, these results are not supported in the Standardized Variance of the Principal Component Scores of Macroeconomic Variables (See Tables 5to7).

\section{Conclusion}

Overall, the results suggest validity but weak applicability of APT in TSE over the study period. This can be seen in the results of the factor analysis which generally find one to three factors being priced over the test periods. The results suggest that maximum $80 \%$ of variance was explained by the factors. The $20 \%$ of variance remains without any explanation. So, there is arbitrage opportunity in the TSE that works in full Shariah economy under the sanctions. This research found out that the thirteen macroeconomic variables identified did poorly in explaining the excess returns of the samples and all of these factors weakly affected stock market returns in different sample size and periods. The financial and economical sanctions had negative impact on the equity returns. However, the findings are not conclusive because risks are difficult to evaluate and often non-quantifiable. The country risk is large; transactions are subject to considerable financial scrutiny.

\section{References}

Alikhani, H. (2000). Sanctioning Iran. (I. B. Tauris, New York).

Black, F., Jensen, and Scholes M. (1972). The Capital Asset Pricing Model: Some Empirical Tests in Studies in the Theory of Capital Markets. Michael C. Jensen, (1th Ed). New York: Praeger, pp. 79-121. 
Burmeister, E. and McElroy. M. (1988). Joint estimation of factor sensitivities and risk premiums for the arbitrage pricing theory. Journal of Finance, Vol. 43:721-33.

Central bank Of Iran. (1991-2008), Monthly Bulletin, 2007-2008.

Chamberlain, G and Rothschilid, M. (1983). Arbitrage, Factor structure and Mean Variance Analysis on Large Asset Markets. Econometrica, 51(5), 1281-1304.

Chen, S-J. and B.Jordan. (1993). Some Empirical Tests in the Arbitrage Pricing Theory: Macro-variables vs. Derived Factors. Journal of Banking and Finance, Vol. 17(North Holland), 65- 89.

Chen, N., Roll, R., Ross, S. A. (1986). Economic Forces and the Stock Market. Journal of Business, 59(1), 383 403.

Clare, A. and Priestly, R. (1998). Risk Factors in the Malaysian Stock Market. Pacific-Basin Finance Journal. 6: 103-114.

Connor, G and Korajczyk, R.(1986). Performance Measurement with the Arbitrage Pricing Theory: A New Framework for Analysis. Journal of Financial Economics. 15: 373-394.

Elton, E. J., Gruber M. J. and Blake, C. R. (1995). Fundamental Economic Variables, Expected Returns, and Bond Fund Performance. Journal of Finance, Vol.1(4), 1227-1256.

Fama, E. F. and Macbeth, J., (1973). Risk, return, and equilibrium: Empirical tests. Journal of Political Economy, Vol. 81(3), 607-636.

Garrett, I and Priestly, R (1997). Do Assumptions about Factor Structure Matter in Empirical Tests of the APT? Journal of business Finance and Accounting. 24(2): 249-260.

Gehr, A. Jr. (1978). Some Tests of Arbitrage Pricing theory. Journal of the Midwest Finance Association, 91-105.

Hakim, S. R., (2008). Properties, Linkages, and the Impact of Sanctions on the Tehran Stock Exchange. ERF 15th Annual Conference: Equity and Economic Development 23rd - 25th November 2008, Egypt.

Kryzanowski L, and To, M. (1983). General Factors Models and Structure of security Returns. Journal of Financing and Quantitative Analysis, Vol.18, 31-52.

Lintner, J. (1965). The valuation of risk assets and the selection of risky investments in stock portfolios and capital budgets. Review of Economics and Statistics, Vol. 47 (2), 13-37.

McElory, M.B., Burmeister, E., and K D Wall (1985). Two Estimators for the APT when Factors are Measured. Economics Letters. 19: 271- 275.

Mohseni, GH. (2007). How we can test APT? Journal of Economic Investigation, University Tehran, Vol.19,65-95.

Mossin, J. (1966). Equilibrium in a Capital Asset Market. Econometrical. 34(4): 768-783.

Nomani, F., and Rahnema, A. (1994). Islamic Economic Systems. London: Zed Books Ltd.

Roll, R., Ross, S. A. (1980). An Empirical Investigation of the Arbitrage Pricing Theory. Journal of Finance. 35 : $1073-1103$

Ross, S. A. (1976). The Arbitrage Theory of Capital Asset Pricing. Journal of Economic Theory. 13: 341 - 360.

Sharpe, W. F. (1964). Factors in NYSE Security Returns, 1931-1979. Journal of Portfolio Management. 8 (2): 5-19.

Tababchnik, B.G. and Fidell, L.S.(1996). Using Multivariate Statistics. (3th edition).New York: Harper and Row,pp.325-378.

Torbat, A. (2006). Impact of Trade and Financial Sanction on Iran. Blacwell Published, UK and Main Street USA. Tehran Stock Exchange. (2009) Yearly Bulletin.

Van Rensburg, P. (2000).Macroeconomic Variables and the Cross-Section of Johannesburg Stock Exchange South African. Journal of Business Management, 31(1), 31-45. 
Table1. Factor analysis and Cross-Sectional Regression of average returns against factor scores coefficients

\begin{tabular}{|c|c|c|c|c|c|}
\hline & $\begin{array}{c}60 \text { Individual } \\
\text { Securities } \\
\end{array}$ & 20 Portfolios & 15 Portfolios & 10Portfolios & 5 Portfolios \\
\hline $\begin{array}{l}\text { No. of Common } \\
\text { Factors }\end{array}$ & 22 & 7 & 4 & 2 & 2 \\
\hline $\begin{array}{l}\text { No. of the Priced } \\
\text { Factors }\end{array}$ & 9 & 6 & 3 & 2 & 2 \\
\hline$\lambda 1$ & $\begin{array}{l}2.25^{* * *} \\
(5.63)\end{array}$ & $\begin{array}{l}8.45^{* * *} \\
(25.8)\end{array}$ & $\begin{array}{c}16.04 * * * \\
(7.2)\end{array}$ & $\begin{array}{c}27.24 * * * \\
(41.15)\end{array}$ & $\begin{array}{l}66.59 * * * \\
(104.55)\end{array}$ \\
\hline$\lambda 2$ & $\begin{array}{l}1.75^{* *} \\
(3.1)\end{array}$ & $\begin{array}{l}9.35^{* * *} \\
(29.52)\end{array}$ & $\begin{array}{c}15.68^{* * *} \\
(4.92)\end{array}$ & $\begin{array}{r}25.93 * * * \\
(57.55)\end{array}$ & $\begin{array}{l}57.77 * * * \\
(75.54)\end{array}$ \\
\hline$\lambda 3$ & $\begin{array}{l}1.84^{* * *} \\
(11.8)\end{array}$ & $\begin{array}{l}8.89 * * * \\
(28.01)\end{array}$ & $\begin{array}{l}8.58^{* *} \\
(2.43)\end{array}$ & & \\
\hline$\lambda 4$ & $\begin{array}{l}2.19^{* * *} \\
(3.9)\end{array}$ & $\begin{array}{l}9.04^{* * * *} \\
(28.05)\end{array}$ & & & \\
\hline$\lambda 5$ & $\begin{array}{l}1.87^{* * *} \\
(5.11)\end{array}$ & $\begin{array}{l}5.02 * * * \\
(15.69)\end{array}$ & & & \\
\hline$\lambda 6$ & $\begin{array}{l}1.39^{* * *} \\
(5.11)\end{array}$ & $\begin{array}{l}0.74 * * \\
(2.38)\end{array}$ & & & \\
\hline$\lambda 7$ & $\begin{array}{l}1.06^{* * *} \\
(7.88)\end{array}$ & & & & \\
\hline$\lambda 8$ & $\begin{array}{l}0.42^{* *} \\
(2.39)\end{array}$ & & & & \\
\hline$\lambda 9$ & $\begin{array}{l}0.36^{* * *} \\
(2.6)\end{array}$ & & & & \\
\hline $\mathrm{d}_{\text {Financial }}$ & $\begin{array}{c}0.95 \\
(1.12)\end{array}$ & $\begin{array}{c}-1.37 * \\
(-1.66)\end{array}$ & $\begin{array}{c}-1.54 \\
(-0.83)\end{array}$ & $\begin{array}{l}-2.68 * * \\
(-2.47)\end{array}$ & $\begin{array}{c}-1.95 \\
(-1.88)\end{array}$ \\
\hline $\mathrm{d}_{\text {Economical }}$ & $\begin{array}{c}0.74 \\
(0.24) \\
\end{array}$ & $\begin{array}{l}-0.63 \\
(-0.77) \\
\end{array}$ & $\begin{array}{c}-0.83 \\
(-0.45) \\
\end{array}$ & $\begin{array}{c}-1.97 * \\
(-1.68) \\
\end{array}$ & $\begin{array}{c}-1.87 \\
(-1.85)^{*}\end{array}$ \\
\hline $\mathrm{F}$ & 89.41 & 404.02 & 452.39 & 1463.33 & 7424.47 \\
\hline Sig.F & $0.00 * * *$ & $0.00 * * *$ & $0.00 * * *$ & $0.00 * * *$ & $0.00^{* * *}$ \\
\hline KMO & 0.63 & 0.76 & 0.80 & 0.83 & 0.85 \\
\hline Adj-R Square & 0.93 & 0.95 & 0.95 & 0.97 & 0.99 \\
\hline
\end{tabular}

Note: N=No. of Factors from factor analysis;

$\mathrm{t}$ - Values in bracket.

Only priced factors at $1 \%, 5 \%$ and $10 \%$ significant level are shown.

*Significant at $10 \%$ level. $\quad * *$ Significant at $5 \%$ level.

*** Significant at $1 \%$ level. 
Table2. Factor analysis and Cross-Sectional Regression of average returns against factor scores coefficients

\begin{tabular}{|c|c|c|c|c|c|}
\hline & 60 Individual Securities & 20 Portfolios & 15 Portfolios & 10Portfolios & 5 Portfolios \\
\hline No. of Common Factors & 15 & 6 & 5 & 2 & 1 \\
\hline No. of the Priced Factors & 8 & 3 & 3 & 2 & 1 \\
\hline$\lambda 1$ & $2.91 * * *$ & $34.76 * * *$ & $26.98 * * *$ & $27.13 * * *$ & $100.12^{* * *}$ \\
\hline$\lambda 2$ & $(4.67)$ & $(32.33)$ & $(9.51)$ & $(20.01)$ & $(225.15)$ \\
\hline$\lambda 3$ & $1.5^{* * *}$ & $24.15^{* * *}$ & $44.35^{* * *}$ & $30.37 * * *$ & $-2.08 * *$ \\
\hline$\lambda 4$ & $(4.04)$ & $(4.58)$ & $(5.80)$ & $(40.86)$ & $(-2.22)$ \\
\hline$\lambda 5$ & $2.82 * * *$ & $-5.74 * * *$ & $-18.26^{* *}$ & & $2.08 * *$ \\
\hline$\lambda 6$ & $(4.45)$ & $(-3.82)$ & $(-2.53)$ & $-4.06 * *$ & $(2.24)$ \\
\hline$\lambda 7$ & $1.05 * * *$ & & & $(-2.26)$ & \\
\hline$\lambda 8$ & $(3.23)$ & -1.20 & -1.43 & $3.60 * *$ & \\
\hline \multirow{12}{*}{$\mathrm{d}_{\text {Economical }} \mathrm{d}_{\text {Financial }}$} & $1.08 * * *$ & $(-0.87)$ & $(-0.29)$ & $(2.12)$ & \\
\hline & $(3.13)$ & $3.02 *$ & 4.74 & & \\
\hline & $1.61 * * *$ & $(1.90)$ & $(1.14)$ & & \\
\hline & $(3.26)$ & & & & \\
\hline & $1.83 * * *$ & & & & \\
\hline & $(5.11)$ & & & & \\
\hline & $1.5^{* * *}$ & & & & \\
\hline & $(4.5)$ & & & & \\
\hline & -1.07 & & & & \\
\hline & $(-0.70)$ & & & & \\
\hline & 1.70 & & & & \\
\hline & $(0.7)$ & & & & \\
\hline $\mathrm{F}$ & 26.00 & 682.81 & 104.49 & 808.34 & 2871.32 \\
\hline Sig.F & $0.00 * * *$ & $0.00 * * *$ & $0.00^{* * *}$ & $0.00^{* * *}$ & $0.00 * * *$ \\
\hline KMO & 0.60 & 0.77 & 0.78 & 0.86 & 0.87 \\
\hline Adj-R Square & 0.84 & 0.98 & 0.98 & 0.98 & 0.99 \\
\hline
\end{tabular}

Note: N=No. of Factors from factor analysis; t- Values in bracket.

Only priced factors at $1 \%, 5 \%$ and $10 \%$ significant level are shown.

*Significant at $10 \%$ level.

** Significant at $5 \%$ level.

*** Significant at $1 \%$ level. 
Table 3. Factor analysis and Cross-Sectional Regression of average returns against factor scores coefficients

\begin{tabular}{|c|c|c|c|c|c|}
\hline & 160 Individual Securities & 20 Portfolios & 15 Portfolios & 10Portfolios & 5 Portfolios \\
\hline No. of Common Factors & 24 & 8 & 5 & 4 & 1 \\
\hline No. of the Priced Factors & 13 & 4 & 3 & 3 & 1 \\
\hline$\lambda 1$ & $2.54 * * *$ & $12.52 * *$ & $22.40 * * *$ & $47.7 * * *$ & $650.19^{* * *}$ \\
\hline$\lambda 2$ & $(16.01)$ & $(2.17)$ & $(7.80)$ & $(13.41)$ & $(36.24)$ \\
\hline$\lambda 3$ & $0.48 * * *$ & $56.66 * * *$ & $28.82 * * *$ & $33.97 * * *$ & \\
\hline$\lambda 4$ & $(2.92)$ & $(10.95)$ & $(19.20)$ & $(16.82)$ & \\
\hline$\lambda 5$ & $0.83 * * *$ & $19.60 * * *$ & $21.59 * * *$ & $16.87 * * *$ & \\
\hline$\lambda 6$ & $(4.9)$ & $(4.5)$ & $(10.16)$ & $(8.4)$ & -32.95 \\
\hline$\lambda 7$ & $1.06^{* * *}$ & $14.45 * *$ & & & $(-0.88)$ \\
\hline$\lambda 8$ & $(7.31)$ & $(5.01)$ & & & -42.77 \\
\hline$\lambda 9$ & $0.86^{* * *}$ & & -0.5 & $-15.13 * * *$ & $(-0.89)$ \\
\hline$\lambda 10$ & $(6.69)$ & & $(-0.15)$ & $(-3.24)$ & \\
\hline$\lambda 11$ & $0.54 * *$ & 4.69 & -1.91 & -1.73 & \\
\hline$\lambda 12$ & $(2.36)$ & $(0.58)$ & $(-0.38)$ & $(-0.28)$ & \\
\hline$\lambda 13$ & $0.52 * * *$ & -4.18 & & & \\
\hline $\mathrm{d}_{\text {Financial }}$ & $(3.28)$ & $(-0.4)$ & & & \\
\hline & $0.27 * *$ & & & & \\
\hline d & $(2.07)$ & & & & \\
\hline & $0.48 * * *$ & & & & \\
\hline & $(3.79)$ & & & & \\
\hline & $0.64 * * *$ & & & & \\
\hline & $(4.85)$ & & & & \\
\hline & $0.32 * *$ & & & & \\
\hline & $(2.60)$ & & & & \\
\hline & $0.22 *$ & & & & \\
\hline & $(1.68)$ & & & & \\
\hline & $0.3 * *$ & & & & \\
\hline & $(2.09)$ & & & & \\
\hline & 0.96 & & & & \\
\hline & $(0.33)$ & & & & \\
\hline & -0.28 & & & & \\
\hline & $(-0.17)$ & & & & \\
\hline $\mathrm{F}$ & 18.52 & 31.25 & 90.43 & 108.00 & 475.33 \\
\hline Sig.F & $0.00^{* * *}$ & $0.00^{* * *}$ & $0.00^{* * *}$ & $0.00 * * *$ & $0.00^{* * *}$ \\
\hline $\mathrm{KMO}$ & 0.63 & 0.68 & 0.75 & 0.76 & 0.77 \\
\hline Adj-R Square & 0.88 & 0.88 & 0.88 & 0.89 & 0.93 \\
\hline
\end{tabular}

Note: N=No. of Factors from factor analysis;

$\mathrm{t}-$ Values in bracket.

Only priced factors at $1 \%, 5 \%$ and $10 \%$ significant level are shown.

*Significant at $10 \%$ level.

** Significant at $5 \%$ level.

*** Significant at $1 \%$ level.

Table 4. Identification of the Macroeconomic Variables Grouped by the Factor Loadings

\begin{tabular}{|lccc|}
\hline & Full Period & First Sub-Period & Second Sub-Period \\
\hline Factor1 & Money supply(M2), Money supply(M1), Central & Oil price, & Trade Balance, \\
& Bank Reserves, Trade balance, & Central Bank Reserves, \\
& Exchange Rate, Oil Price & Export of crude oil, & Crude oil Production, \\
& & Consumer Price Index & Eolume of stock transaction, \\
& & & Exchange Rate, \\
Factor2 & Consumer Price Index, GDP & TEPIX, Central Bank Reserves, & Money supply(M2), Money supply(M1), \\
& Crude oil production & GDP & Consumer Price Index, GDP \\
Factor3 & TEPIX, Volume of stock transaction & Trade balance, Profit rate proxy, & Oil Price, Crude oil production, \\
& & Exchange Rate & Export of crude oil \\
Factor4 & Export of crude oil, Profit rate proxy & Money supply(M2) & Profit rate proxy \\
& & Money supply(M1) & \\
Factor5 & - & Volume of stock transaction & - \\
\hline
\end{tabular}


Table 5. Canonical Correlation Analysis in the 17-Year Full period

\begin{tabular}{|lccccc|}
\hline & 60 Individual Securities & 20 Portfolios & 15 Portfolios & 10 Portfolios & 5 Portfolios \\
\hline FSMR & FSMR44 FFFFFFF & FSMR2 & FSMR2 & FSMR2 & FSMR2 \\
Shared Variance & $11 \%$ & $14 \%$ & $33 \%$ & $50 \%$ & $50 \%$ \\
Redundancy & $1.9 \%$ & $1.6 \%$ & $2.3 \%$ & $5.9 \%$ & $3.6 \%$ \\
& & & & & \\
\hline FMACRO & FMACRO 3 & FMACRO & FMACRO 4 & FMACRO2 & FMACRO4 \\
& FMACRO4 & & & FMACRO 4 & \\
Shared Variance & $25 \%$ & $25 \%$ & $25 \%$ & $25 \%$ & $25 \%$ \\
Redundancy & $4.3 \%$ & $2.9 \%$ & $1.7 \%$ & $2.9 \%$ & $1.8 \%$ \\
\hline
\end{tabular}

Note: FSMR is Principal Component Scores of the Stock Market Returns.

FMACRO is Principal Component Scores of the Macroeconomic Variables.

Shared Variance is Standardized Variance of the Principal Component Scores of Stock Market Returns Explained by their Own Canonical Variate.

Redundancy is Standardized Variance of the Principal Component Scores of Stock Market Returns Explained by the Opposite Canonical Variate.

Table 6. Canonical Correlation Analysis in the First Sub-period

\begin{tabular}{|lcccc|}
\hline & 60 Individual Securities & 20 Portfolios & 15 Portfolios & 10 Portfolios \\
\hline FSMR & FSMR34 & FSMR2 & FSMR 1 & FSMR2 \\
Shared Variance & $11 \%$ & $33 \%$ & $33 \%$ & $50 \%$ \\
Redundancy & $1.9 \%$ & $5.3 \%$ & $4.06 \%$ & $5.6 \%$ \\
\hline FMACRO & FMACRO2 & FMACRO2 & FMACRO2 & FMACRO2 \\
& FMACRO4 & FMACRO5 & FMACRO4 & FMACRO4 \\
& & & FMACRO5 & FMACRO5 \\
Shared Variance & $20 \%$ & $20 \%$ & $19.8 \%$ & $19.7 \%$ \\
Redundancy & $3.3 \%$ & $3.19 \%$ & $2.42 \%$ & $2.2 \%$ \\
\hline
\end{tabular}

Note: FSMR is Principal Component Scores of the Stock Market Returns.

FMACRO is Principal Component Scores of the Macroeconomic Variables.

Shared Variance is Standardized Variance of the Principal Component Scores of Stock Market Returns Explained by their Own Canonical Variate.

Redundancy is Standardized Variance of the Principal Component Scores of Stock Market Returns Explained by the Opposite Canonical Variate.

Table7. Canonical Correlation Analysis in the Second Sub-period

\begin{tabular}{|lcccc|}
\hline & 60 Individual Securities & 20 Portfolios & 15 Portfolios & 10 Portfolios \\
\hline FSMR & FSMR14 FFFFFFF & FSMR2 & FSMR1 & FSMR1 \\
Shared Variance & $7 \%$ & $25 \%$ & $33 \%$ & $32.8 \%$ \\
Redundancy & $2.2 \%$ & $4.9 \%$ & $3.1 \%$ & $3.1 \%$ \\
\hline FMACRO & FMACRO2 & FMACRO2 & FMACRO2 & FMACRO2 \\
& & FMACRO3 & FMACRO3 & FMACRO3 \\
Shared Variance & $25 \%$ & $26 \%$ & $25 \%$ & $26 \%$ \\
Redundancy & $7.3 \%$ & $4.2 \%$ & $2.3 \%$ & $2.5 \%$ \\
\hline
\end{tabular}

Note: FSMR is Principal Component Scores of the Stock Market Returns.

FMACRO is Principal Component Scores of the Macroeconomic Variables.

Shared Variance is Standardized Variance of the Principal Component Scores of Stock Market Returns Explained by their Own Canonical Variate.

Redundancy is Standardized Variance of the Principal Component Scores of Stock Market Returns Explained by the Opposite Canonical Variate. 